\title{
Factors Associated with Mortality Among Elderly People in the COVID-19 Pandemic (SARS-CoV-2): A Systematic Review and
}

\section{Meta-Analysis}

Vicente Alves $^{1,2}$, Francine Casemiro ${ }^{3}$, Bruno Araujo ${ }^{1}$, Marcos Lima ${ }^{1}$, Rayssa Oliveira ${ }^{1}$, Fernanda Fernandes ${ }^{1}$, Ana Vitória Gomes ${ }^{1}$, Dario Gregori ${ }^{2}$

\author{
Catholic of de Brasília, Brazil. \\ 2 Unit of Biostatistics, Epidemiology and Public Health at Padova University, Italy \\ 3 University of São Paulo, Brazil \\ * Correspondence: vicerap@gmail.com.
}

\begin{abstract}
The objective of this meta-analysis was to evaluate the factors associated with mortality of elderly Italians diagnosed with the new coronavirus who resided in institutions or who were hospitalized as a result of the disease. Methods: A systematic review following the recommendations of The Joanna Briggs Institute (JBI), where the PEO strategy was utilized - Population, Exposure and Outcome. P, being the elderly over 65 years old. E, the SARS-CoV_2 pandemic. O, mortality. The NCBI / PubMed, LILACS, EMBASE and CINAHL databases were used until July 31, 2020.; Results: Five Italian studies were included in the meta-analysis, with the number of elderly people varying between 18 and 1591 patients. The main morbidities presented by the elderly in the studies were: dementia, diabetes, chronic kidney disease and hypertension. Conclusions: The factors associated with the mortality of elderly Italian people diagnosed with SARS-CoV-2 who lived in institutions or who were hospitalized because of the disease were evaluated. It was found that dementia, diabetes, chronic kidney disease and hypertension are the main the main diagnosed diseases for mortality in elderly people with Covid-19.
\end{abstract}

Keywords: SARS-CoV-2; COVID-19; Non-Communicable Chronic Diseases (NCCDs); Clinical features; Institucionalized or hospitalized elderly; meta-analysis.

\section{Introduction}

One of the greatest achievements of humanity has been longevity, which, although there are still differences between countries, is influenced by each socioeconomic context, in general by the progress in the population's health markers. Achieving old age, which was once the privilege of a few, has now become one of the world's main goals and challenges(1).

In this way, aging has been presented as a global phenomenon, based on a success story for public health policies and socioeconomic development. However, there are new challenges for society that needs to adapt to this new scenario, in order to maximize the functional capacity and health of the elderly, as well as their social and safety participation (1). In view of this, there are social consequences of this aging on public health issues, among European countries, such as Italy(2) where the profile of the elderly population includes a group with a high prevalence of non-communicable chronic diseases (NCCDs) and associated comorbidities(1). In Italy, aging, despite being also an intense and growing process, considered the second country with the largest number of elderly people(2), has 
a mortality rate that has been decreasing by more than $50 \%$ in the last 30 years, mainly due to the impact on the reduction of cardiovascular diseases(3).

The Covid-19 pandemic (SARS-CoV-2) has considerable mortality in populations considered at risk, such as the elderly population, especially those who were institutionalized, which made social isolation difficult in these situations. The vulnerability of this population is linked to the physiological aspects of aging, which impacts the effectiveness of the immune system, triggering morbidity and mortality from infectious diseases(4).

Thus, it is necessary to investigate what are the main factors that make these people more vulnerable to death. This fragility is a condition that worsens with advancing age and with COVID-19, especially for those hospitalized elderly, who tend to be more accentuated with the classic symptoms of the disease(5).

Several studies began to be carried out in different contexts, with scientific evidence and statistical data that pointed in certain directions. Contributing to the advancement of knowledge about its reach and the factors associated with their mortality has become a challenge for all researchers. In this specific case, it was proposed to carry out a systematic review of studies published in Italy between March and July 2020, with the intention of raising such factors. The selection of the Italian texts that were published is due to the fact that the local transmission took place first in Italy and, soon after, in the other European regions(6).

In Italy, the contagion outbreak started on February 20, reaching $428 \%$ of confirmed cases in the following days. Residential facilities for the elderly were the hardest hit, according to data released by the Istituto Superiore di Sanità(7). The elderly who died in these residential establishments due to Covid-19, who underwent the Reverse Transcription Polymerase Chain Reaction (RT-PCR) exam would be around $7.4 \%$ of all deaths in the period. When adding to this data, all those who died with flu symptoms (without any objective assessment), deaths reached $41.2 \%$. The survey was carried out by ISS by sending a questionnaire to 3,417 establishments to which 1,356 responded to a total of 97,521 elderly residents (8).

Based on this, the objective of this study was to synthesize the factors associated with the mortality of Italian elderly people diagnosed with the new coronavirus who lived in institutions or who were hospitalized as a result of the disease.

\section{Materials and Methods}

Search strategy and selection criteria

The choice of the systematic review format was based on the recommendations of The Joanna Briggs Institute (JBI), following the nine steps for its development: 1) Construction of the preliminary research protocol; 2) Formulation of the review question; 3) Definition of inclusion and exclusion criteria; 4) Search strategy; 5) Selection of studies for inclusion; 6) Data extraction; 7) Synthesis of the data; 8) Narrative summary; 9) References(9).

This study used articles of public and free access, located in the databases of scientific literature. Primary studies on the mortality of Italian elderly with a diagnosis of the new coronavirus were selected, publications in English, Italian and Spanish in publications 
that carried out quantitative and qualitative analysis. For the formulation of the research question, the PEO strategy was used - Population, Exposure and Outcome (10). It was determined that the "Population" (P) would be the elderly over 65 years, the "Exposure" (E), the SARS-CoV_2 pandemic; and the "Outcome" $(\mathrm{O})$, mortality. Thus, the guiding question of this study was: "What are the factors related to the mortality of Italian elderly people diagnosed with the Covid-19 (SARS-CoV-2) disease?".

Thus, the inclusion criteria for the selection of articles were:

- primary studies on the mortality of elderly people diagnosed with the new coronavirus;

- studies in English, Spanish and Italian.

Once the inclusion criteria were established, these were the exclusion criteria:

- studies that were not of Italian elderly people;

- studies on the elderly who were not institutionalized or hospitalized; and,

- studies that did not answer the guiding question of the systematic review.

Data extraction and analysis

The search for publications happened in July of 2020 in the databases National Center for Biotechnology Information (NCBI / PubMed), LILACS, Excerpta Medica Database (EMBASE), Cumulative Index to Nursing and Allied Health Literature (CINAHL). The search strategy occurred by combining controlled and uncontrolled descriptors, according to the indication offered in each database. To search for articles on PubMed (M Lima, R Oliveira, F Fernandes, AV Gomes), controlled descriptors from Medical Subject Headings (MeSH) were used. Heading-MH was consulted for the CINHAL base. Embase Subject Headings (EMTREE) was used to search EMBASE and Health Sciences Descriptors (DeCS) were used to search LILACS. For this search, "aged", "coronavirus infections" and "mortality" were used. The Boolean operator "AND" was used in all combinations as follows: "aged AND aged 80 and over AND coronavirus infections AND mortality". There was no time limit for publication. For the selection of articles, the Rayyan application, developed by the QCRI (Qatar Computing Research Institute), was used, which helps in systematic reviews, facilitating the selection process for reading articles, which took place in three stages: in the first one, the search in the databases of data; secondly, the reading of the title and the abstract, when two researchers (F Casemiro e B Araújo) performed the bibliographic search and independently extracted data from the included studies. Disagreements were resolved by the third investigator (V Alves) or by consensus. So that the purpose was to separate the studies for this third stage, in which the full reading of the articles occurred, aiming to select those that were in agreement with the inclusion criteria (11).

In the development of the search and selection of articles, from the databases to the selection of studies by reading titles and abstracts or full text, the PRISMA protocol was used (12) (Figure 1), in order to guarantee the rigor of the systematic review (11).

Figure 1: Flow diagram of the number of studies selected and included in the metaanalysis. 


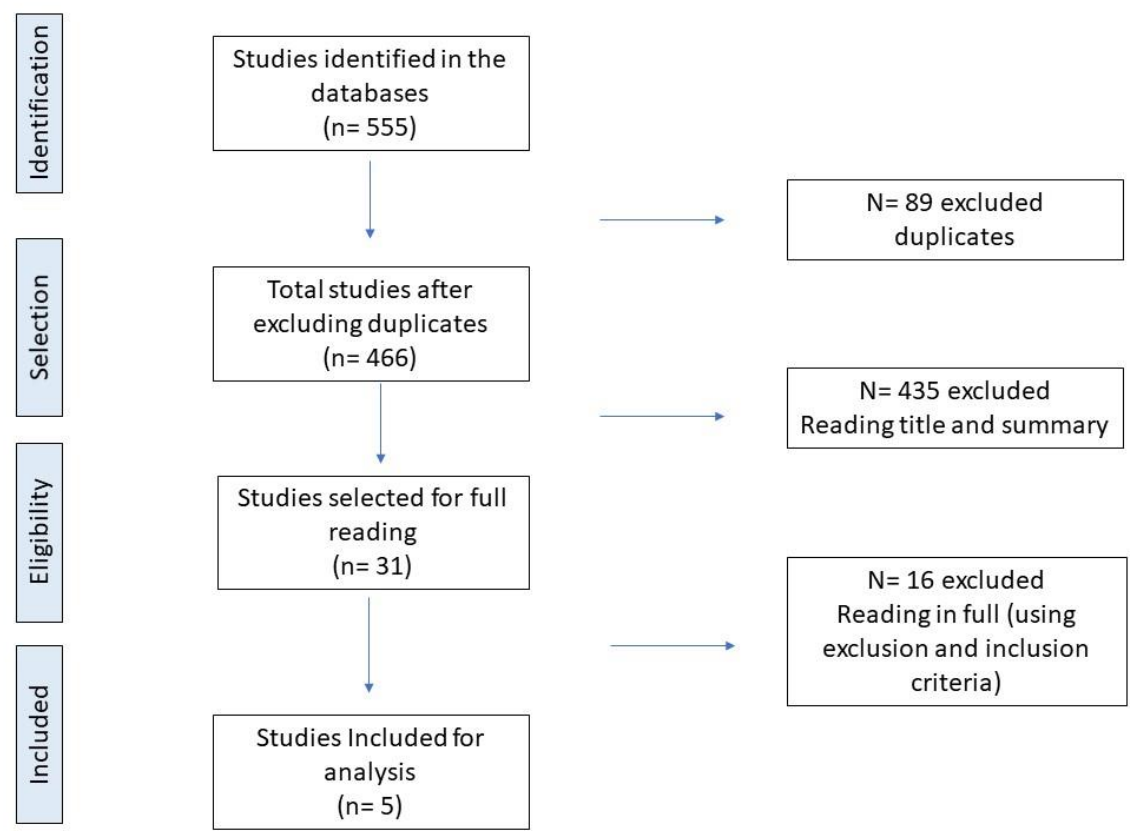

From the findings, the results were organized by performing a descriptive synthesis of the data, shown in Table 1.

The meta-analysis was conducted using the Stata software, version 16.0 (D Gregorio). Initially, the mortality rate was estimated using the number of deaths as the numerator and the total number of the analyzed sample as the denominator, multiplied by the constant $100 \%$. The grouped meta-analysis of the mortality rate was performed using random effects models (13). Heterogeneity between studies was assessed using the Isquare $\left(I^{2}\right)(14)$.

Next, the factors associated with mortality were analyzed, with the outcome being death. Thus, two groups were compared (non-survivors versus survivors). The following quantitative variables were considered as predictors: age, Charlson Index, lymphocytes, CRP, glucose, albumin, ALT, AST, bilirubin, GGT, lipase, CK, LDH, sodium, potassium, clhoride, urea, creatinine, hscTnI, PT / INR, APTT, D-dimer, Ferritin, Hb, WBC, neutrophils and platelets. In the study that presented data such as median and interquartile range (IIQ) (15) transformation was done in mean and standard deviation (SD) (16). The following qualitative variables were considered to be predictors: male gender, chronic diseases, cancer, diabetes, cardiovascular diseases, Chronic Obstructive Pulmonary Disease (COPD), immunodeficient, Chronic Kidney Disease (CKD), metabolic disease, obesity, hypertension, familial hypercholesterolemia (FH), dementia and smoking. Variables related to the use of drugs and therapies were excluded from the risk factor analyzes, since this review would not address clinical trials.

The effect size was reported as standardized mean difference (SDM) for quantitative variables or relative risk (RR) for qualitative variables. All of these measures were followed up with a 95\% confidence interval (17). Heterogeneity between studies was assessed using the I-square $\left(\mathrm{I}^{2}\right)(14)$. Fixed or random effect models were used depending on heterogeneity. Variables with $p$-value $<0.05$ were considered statistically significant.

The protocol for this article was published in the International Prospective Register Of Systematic Reviews, PROSPERO, in August 2020, under the register: CRD42020201790. 


\section{Results}

The number of elderly people varied between 18 (18) and 1591 (19) patients. The objectives of the publications are similar when making a descriptive analysis of the elderly and the factors associated with the new coronavirus.

The main morbidities presented by the elderly in the studies were: dementia (20) diabetes $(19,21)$, chronic kidney disease (19), hypertension (21), showing that NCCs had a predominant factor in these cases.

Table 1: Descriptive synthesis of the data 
The Figure 2 shows the meta-analysis of the mortality rate found. A mortality rate of 27.7\% was observed (IC95\%: 15,7-41,57\%), with high heterogeneity between studies (I²: $97,71 \% ; \mathrm{p}<0,001)$.

\begin{tabular}{|c|c|c|c|c|}
\hline Author / Year & Journal & Aim & $\begin{array}{l}\text { Elderly } \\
\text { sample }\end{array}$ & Sample location \\
\hline$(20)$ & $\begin{array}{l}\text { Journal of } \\
\text { Nutrition, } \\
\text { Health and } \\
\text { Aging }\end{array}$ & $\begin{array}{l}\text { To evaluate the } \\
\text { prevalence, clinical } \\
\text { characteristics, and } \\
\text { outcomes of dementia in } \\
\text { individuals hospitalized } \\
\text { for the infection of } \\
\text { COVID19. }\end{array}$ & 627 & $\begin{array}{l}\text { Hospitals and } \\
\text { nursing homes in } \\
\text { the province of } \\
\text { Brescia, Northern } \\
\text { Italy. }\end{array}$ \\
\hline (18) & $\begin{array}{l}\text { Future On- } \\
\text { cology }\end{array}$ & $\begin{array}{l}\text { Describe the case of } 25 \\
\text { cancer patients who were } \\
\text { infected with COVID- } 19 \text {. }\end{array}$ & 18 & $\begin{array}{l}\text { Piacenza's general } \\
\text { hospital, Northern } \\
\text { Italy. }\end{array}$ \\
\hline$(21)$ & $\begin{array}{l}\text { Interna- } \\
\text { tional Jour- } \\
\text { nal of Envi- } \\
\text { ronmental } \\
\text { Research } \\
\text { and Public } \\
\text { Health }\end{array}$ & $\begin{array}{l}\text { Describe the clinical } \\
\text { characteristics of patients } \\
\text { who died after a positive } \\
\text { test for SARS-CoV-2 } \\
\text { infection and evaluate the } \\
\text { influence of health } \\
\text { conditions associated with } \\
\text { the outcome of death. }\end{array}$ & 573 & Sardinia, Italy \\
\hline (22) & $\begin{array}{l}\text { Clinical } \\
\text { Chemistry } \\
\text { and Labor- } \\
\text { atory Medi- } \\
\text { cine } \\
\text { (CCLM) }\end{array}$ & $\begin{array}{l}\text { Describe laboratory } \\
\text { findings in a group of } \\
\text { Italian patients with } \\
\text { COVID-19 in the } \\
\text { Valcamonica area, and } \\
\text { correlate the abnormalities } \\
\text { with severity of the } \\
\text { disease. }\end{array}$ & 518 & $\begin{array}{l}\text { Emergency } \\
\text { Department of the } \\
\text { Valcamonica } \\
\text { Hospital (Esine, } \\
\text { Brescia, Lombardia, } \\
\text { Italy) }\end{array}$ \\
\hline (19) & $\begin{array}{l}\text { Hyperten- } \\
\text { sion }\end{array}$ & $\begin{array}{l}\text { Check if renin- } \\
\text { angiotensin, the system } \\
\text { inhibitors, are related to } \\
\text { the serious results of } \\
\text { COVID-19. }\end{array}$ & 1591 & Multicenter study. \\
\hline
\end{tabular}


Figure 2. Mortality rate in the elderly obtained in the meta-analysis

\begin{tabular}{|c|c|c|c|c|c|c|c|c|}
\hline Study & & & & & & & Lethality $(95 \% \mathrm{Cl})$ & $\%$ Weight \\
\hline Deiana et al. (2020) & & $\rightarrow-$ & & & & & $19.42(15.74,23.55)$ & 21.18 \\
\hline Stroppa et al. (2020) & & & & & & & $36.00(17.97,57.48)$ & 15.62 \\
\hline laccarino et al. (2020) & $\rightarrow$ & & & & & & $11.82(10.27,13.50)$ & 21.55 \\
\hline Bonetti et al. (2020) & & & & & $\rightarrow-$ & & $48.61(40.20,57.08)$ & 20.30 \\
\hline Bianchetti et al. (2020) & & & & & & & $30.94(27.34,34.72)$ & 21.35 \\
\hline Overall $(\wedge 2=97.71 \%, p=0.00)$ & & & & & & & $27.68(15.66,41.57)$ & 100.00 \\
\hline$T$ & $T$ & $T$ & $T$ & $T$ & $T$ & $T$ & & \\
\hline 0 & 10 & 20 & 30 & 40 & 50 & 60 & & \\
\hline
\end{tabular}

The meta-analysis was conducted for each predictor variable, being stratified into quantitative and qualitative variables.

The Table 2 shows the descriptive analysis of the quantitative variables, according to the group of survivors and non-survivors, and Table 3 the effect size, in SDM and 95\% CI, of the variables in mortality.

Table 2. Descriptive analysis of quantitative variables, according to group of survivors and non-survivors

\begin{tabular}{lcccccc}
\hline Variables & \multicolumn{3}{c}{ Non-survivors } & \multicolumn{3}{c}{ Survivors } \\
\cline { 2 - 6 } & $\mathbf{N}$ & Mean & SD & N & Mean & SD \\
\hline Age (years) & & & & & & \\
Iacarinno et al. (2020) & 188 & 79.6 & 0.8 & 1.304 & 64.7 & 0.4 \\
Stroppa et al. (2020) & 9 & 74.44 & 7.21 & 16 & 68.38 & 10.16 \\
Bonetti et al. (2020) & 70 & 75.4 & 14.99 & 74 & 62.63 & 14.97 \\
Charlson Index & & & & & & 2.63 \\
Iacarinno et al. (2020) & 188 & 4.37 & 0.14 & 1.403 & & 0.05 \\
\hline
\end{tabular}

$\mathrm{N}$ : sample size in each group; $\mathrm{SD}=$ Standard deviation

Table 3. Meta-analysis of factors associated (quantitative variables) with mortality

\begin{tabular}{lcccc}
\hline \multicolumn{1}{c}{ Variables } & SMD $(\mathbf{9 5 . 0} \% \mathbf{C I})$ & $\mathbf{I}^{\mathbf{2}}$ & $\mathbf{Z}$ & p-value \\
\hline Age (years) & $3.10(2.79 ; 3.40)$ & $99.9 \%$ & 19.76 & $<\mathbf{0 . 0 0 1}$ \\
Charlson Index & $1.74(1.56 ; 1.92)$ & - & 19.33 & $<\mathbf{0 . 0 0 1}$ \\
\hline
\end{tabular}

SDM: Standardized mean difference; Z=Estatística Z da metanálise; I²: I-square; $95.0 \%$ CI: 95\% Confidence Interval.

The analysis of quantitative variables showed that mortality increased with increasing age (SMD: 3.10; 95.0\% CI: 2.79; 3.40), from the Charlson Index (SMD: 1.74; 95.0\% CI: $1.56 ; 1.92$ ) (Table 2). 
The Table 4 shows the descriptive analysis of qualitative variables, according to the group of survivors and non-survivors, and Table 5 the effect size, in RR and 95\% CI, of the variables in mortality.

The analysis of quantitative variables showed that the risk of mortality was higher in individuals with diabetes (RR: 1.90; 95.0\% CI: 1.53; 2.37), DPOC (RR: 2.19; 95.0\% CI: 1.54; 3.10), with chronic kidney disease (RR: 3.96; 95.0\% CI: 2.65; 5.91), with hypertension (RR: 1.37; 95.0\% CI: 1.24; 1.51), HF (RR: 3.27; 95.0\% CI: 2.49; 4.29) and with dementia (RR: 3.67; 95.0\% CI: $2.43 ; 5.55)$ (Table 4 ).

Table 4. Descriptive analysis of qualitative variables according to group of survivors and non-survivors

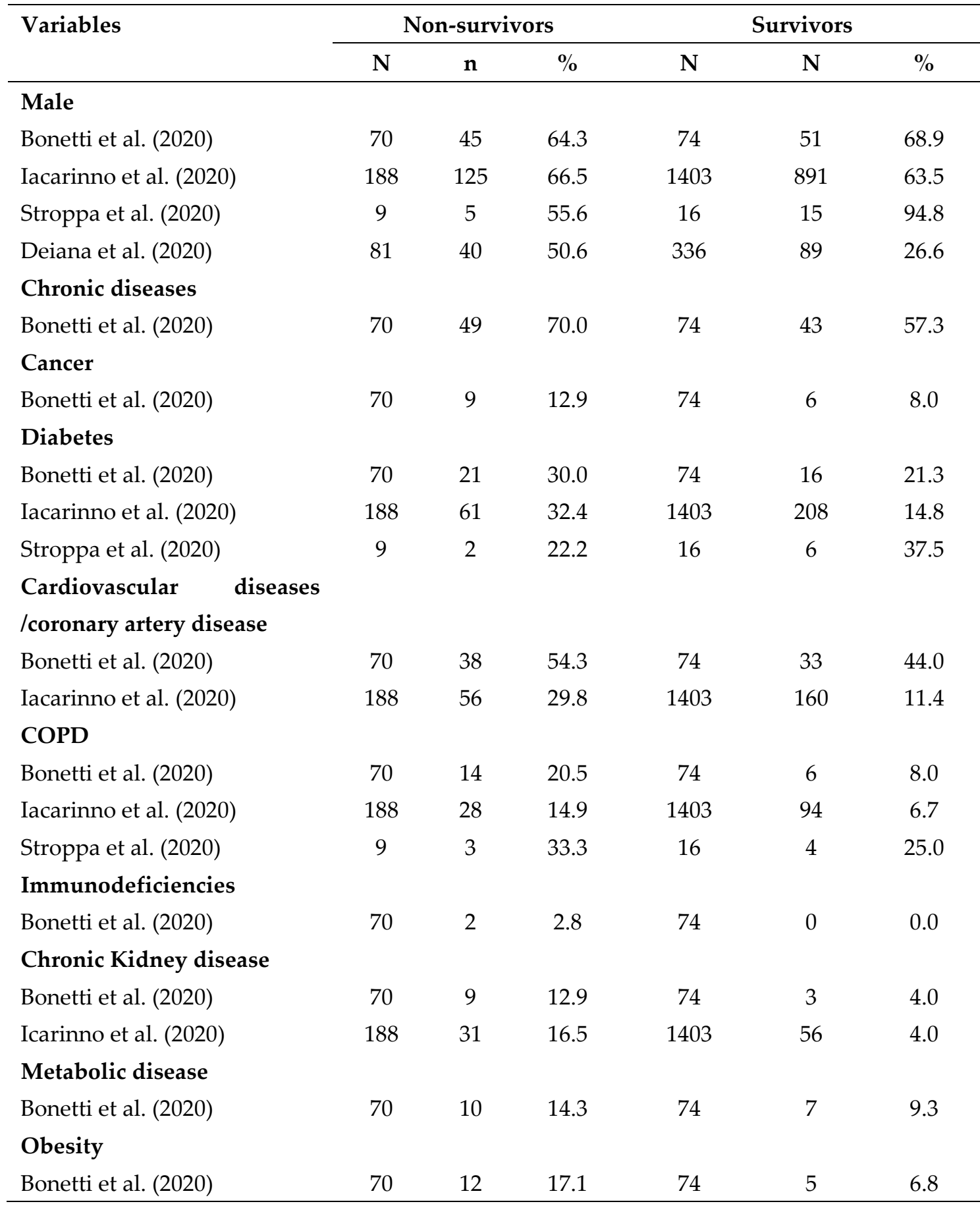




\begin{tabular}{lcccccc}
\hline $\begin{array}{l}\text { Iacarinno et al. (2020) } \\
\text { Hypertension }\end{array}$ & 188 & 12 & 6.4 & 1403 & 90 & 6.4 \\
$\begin{array}{l}\text { Iacarinno et al. (2020) } \\
\begin{array}{l}\text { Stroppa et al. (2020) } \\
\text { HF }\end{array}\end{array}$ & 188 & 138 & 72.9 & 1403 & 737 & 52.5 \\
$\begin{array}{l}\text { Iacarinno et al. (2020) } \\
\text { Dementia }\end{array}$ & 188 & 57 & 30.3 & 1403 & 130 & 9.3 \\
$\begin{array}{l}\text { Bianchetti et al. (2020) } \\
\text { Smoking }\end{array}$ & 194 & 51 & 26.3 & 433 & 31 & 7.2 \\
Stroppa et al. (2020) & 9 & 4 & 44.4 & 16 & 9 & 56.3 \\
\hline
\end{tabular}

$\mathrm{N}$ : sample size in each group; $\mathrm{n}$ : absolute total of elderly people; Relative total\% of elderly.

Table 5. Meta-analysis of factors associated (quantitative variables) with mortality

\begin{tabular}{lcccc}
\hline \multicolumn{1}{c}{ Variables } & $\mathbf{R R}(\mathbf{9 5 . 0} \% \mathbf{C I})$ & $\mathbf{I}^{\mathbf{2}}$ & $\mathbf{Z}$ & p-value \\
\hline Male & $0.98(0.67 ; 1.43)$ & 89.3 & 0.10 & 0.919 \\
Chronic diseases & $1.20(0.94 ; 1.54)$ & - & 1.48 & 0.139 \\
Cancer & $1.60(0.60 ; 4.23)$ & - & 0.92 & 0.356 \\
Diabetes & $1.90(1.53 ; 2.37)$ & 62.7 & 5.73 & $<\mathbf{0 . 0 0 1}$ \\
Cardiovascular & $1.80(0.85 ; 3.80)$ & 92.0 & 1.53 & 0.125 \\
diseases/coronary artery disease & & & & \\
COPD & $2.19(1.54 ; 3.10)$ & 0.0 & 4.39 & $<\mathbf{0 . 0 0 1}$ \\
Immunodeficiencies & $5.28(0.26 ; 108.12)$ & - & 1.08 & 0.280 \\
Chronic Kidney disease & $3.96(2.65 ; 5.91)$ & 0.0 & 6.73 & $<\mathbf{0 . 0 0 1}$ \\
Metabolic disease & $1.51(0.60-3.75)$ & - & 0.89 & 0.374 \\
Obesity & $1.28(0.78 ; 2.10)$ & 60.8 & 0.99 & 0.322 \\
Hypertension & $1.37(1.24 ; 1.51)$ & 69.3 & 6.25 & $<\mathbf{0 . 0 0 1}$ \\
HF & $3.27(2.49 ; 4.29)$ & - & 8.55 & $<\mathbf{0 . 0 0 1}$ \\
Dementia & $3.67(2.43 ; 5.55)$ & - & 6.17 & $<\mathbf{0 . 0 0 1}$ \\
Smoking & $0.74(0.32-1.71)$ & - & 0.70 & 0.483 \\
\hline
\end{tabular}

RR: Relative risk; Z= Z statistic of meta-analysis; I: I-square; 95.0\% CI: 95\% Confidence Interval.

\section{Discussion}

This study aimed to synthesize the factors associated with mortality of elderly Italians diagnosed with the new coronavirus who were institutionalized or hospitalized. The data showed that diabetes, Chronic Obstructive Pulmonary Disease, hypertension and dementia are morbidities that considerably increase the risk of death in the elderly.

ISTAT, in its 2020 May $4^{\text {th }}$ report, states that the impact of Covid-19 is greater in people with extremely compromised health conditions, causing the mortality of these people to happen in a shorter time. The document also reports that, in some cases, Covid19 may not be the leading cause of death, but a contributing factor in overall mortality (7). There are a series of phenomena and dynamics that affect the current state of health of 
Italians, such as the aging of the population, the increase in risk factors, the NCCDs, "the phenomenon of vaccination hesitation, the threat of antimicrobial resistance, the difficulties of access to innovation, the shortage of doctors, the lack of regional homogeneity and the delay in digitizing the health system that affect the system as a whole (23).

Italy has the lowest prevalence rate, by age, for Chronic Obstructive Pulmonary Disease and cardiovascular disease (23) and these were the diseases that increased mortality among the elderly in the articles analyzed. On the other hand, the country has the highest prevalence rate by age for dementia. As aging progresses, the risk of this diagnosis increases. It is a progressive neurodegenerative syndrome characterized by a cognitive decline that limits social functions and activities of daily living (24). In addition to having an important impact on the quality of life of these people, dementia was also shown to be a risk factor for mortality in elderly people with Covid-19.

\section{Conclusions}

At the end of this review, it is believed that the objective proposed for this study had been achieved, to synthesize the factors associated with mortality of elderly Italians diagnosed with the new coronavirus who lived in institutions or who were hospitalized as a result of the disease. In addition, it is expected that the development of public policies takes into account the new reality that profoundly marked humanity with the pandemic.

The NCCDs when associated with SARS-Co2 are death factors in the elderly. This data is fundamental for the elaboration of public policies, health promotion practices and prevention of chronic diseases throughout aging. In addition, the planning of prevention strategies against coronavirus for the elderly population with NCCDS, Chronic Obstructive Pulmonary Disease and Dementia must have a clear and precise target to prevent so many deaths from occurring among the elderly.

Certainly, it will not be possible to think of more houses or institutions that shelter elderly people who do not take into account the greater risks that life in a very large community has for the coexistence and contagion of these diseases. It will be necessary to think creatively about new living spaces, new ways of handling health professionals and operators in these establishments.

The vaccination priorities for this public established by all governments refer to a public policy that was touched by the social movement that reverberated around the world when several army trucks transported the burial coffins in the Italian city of Bergamo in March 2020 The mortality that reached the elderly who lived in institutions of socio-sanitary care or in hospitals showed the true face of the meeting between NCDs and SARS-Cov2.

With vaccination slowly arriving in each country, as the pharmaceutical industry manages to deliver enough doses and countries have an efficient logistics of distribution and application of the drug, it is hoped that all this can pass and that this time lived with a lot of pain and suffering for many families serves for the learning and growth of the authorities and new public policies aimed at the elderly.

The most important limitation of this research is the small number of articles found in Italy, which prevented further analysis. In addition, aspects related to chronic diseases 
should be considered in future studies, since these aspects impact on the mortality of elderly people with COVID-19.

\section{Patents}

Funding: This study was funded by the government agency of the Federal District (Brazil); Research Support Foundation of the Federal District (FAP-DF).

Conflicts of Interest “The authors declare no conflict of interest."

\section{References}

1. WHO. World report on ageing and health [Internet]. 2015 [cited 2021 Feb 19]. p. 260. Available from: https://apps.who.int/iris/bitstream/handle/10665/186463/9789240694811_eng.pdf;jsessionid=8F478F65553AAA7B83E7E68BB 6F7766E?sequence $=1$

2. Piccininni M, Rohmann JL, Foresti L, Lurani C, Kurth T. Use of all cause mortality to quantify the consequences of covid-19 in Nembro, Lombardy: descriptive study. BMJ [Internet]. 2020 May 14;369:m1835. Available from: http://www.bmj.com/content/369/bmj.m1835.abstract

3. Istituto Superiore di Sanità. L'epidemiologia per la sanità pubblica - Malattie cardiovascolari [Internet]. 2020. Available from: https://www.epicentro.iss.it/cardiovascolare/

4. Granda EC, Cunha SGS, Silva, Michele Fabiana da Campos KFC. COVID-19 IN ELDERLY: WHY ARE THEY MORE VULNERABLE TO THE NEW CORONAVIRUS? Brazilian J Dev. 2021;7(4):10.

5. Knopp P, Miles A, Webb TE, Mcloughlin BC, Mannan I, Raja N, et al. Presenting features of COVID-19 in older people: relationships with frailty, inflammation and mortality. Eur Geriatr Med [Internet]. 2020;11(6):1089-94. Available from: https://doi.org/10.1007/s41999-020-00373-4

6. Nadeau SA, Vaughan TG, Scire J, Huisman JS, Stadler T. The origin and early spread of SARS-CoV-2 in Europe. Proc Natl Acad Sci [Internet]. 2021 Mar 2;118(9):e2012008118. Available from: http://www.pnas.org/content/118/9/e2012008118.abstract

7. Istituto Nazionale di Statistica. Impacto dell'epidemia COVID-19 sulla mortalità totale Della Popolazione residente primo trimestre 2020. 2020.

8. Pesaresi F. Covid-19. La mortalità nelle strutture residenziali per anziani. 7 luglio. 2020.

9. Aromataris E, Munn Z. Chapter 1: JBI Systematic Reviews. In: JBI Manual for Evidence Synthesis. JBI; 2020.

10. Moola S, Munn Z, Tufanaru C, Aromataris E, Sears K, Sfetc R, et al. Chapter 7: Systematic Reviews of Etiology and Risk. In: JBI Manual for Evidence Synthesis. JBI; 2020.

11. Ouzzani M, Hammady H, Fedorowicz Z, Elmagarmid A. Rayyan - a web and mobile app for systematic reviews. Syst Rev. 2016 Dec;5(1):210.

12. Moher D, Liberati A, Tetzlaff J, Altman DG. Preferred Reporting Items for Systematic Reviews and Meta-Analyses: The PRISMA Statement. PLoS Med. 2009 Jul;6(7):e1000097.

13. Nikolakopoulou A, Mavridis D, Salanti G. Demystifying fixed and random effects meta-analysis. Evid Based Ment Heal. 2014;17(2):53-7.

14. Hippel PT von. The heterogeneity statistic I2 can be biased in small meta-analyses. BMC Med Res Methodol. 2015;15:35.

15. Bonetti G, Manelli F, Patroni A, Bettinardi A, Borrelli G, Fiordalisi G, et al. Laboratory predictors of death from coronavirus disease 2019 (COVID-19) in the area of Valcamonica, Italy. Clin Chem Lab Med. 2020;58(7):1100-5.

16. Wan X, Wang W, Liu J, Tong T. Estimating the sample mean and standard deviation from the sample size, median, range and/or interquartile range. BMC Med Res Methodol. 2014;14(1):1-13.

17. Martins-Filho P, Tavares CSS, Santos V. Factors associated with mortality in patients with COVID-19. A quantitative evidence 
synthesis of clinical and laboratory data. Eur J Intern Med. 2020;

18. Stroppa EM, Toscani I, Citterio C, Anselmi E, Zaffignani E, Codeluppi M, et al. Coronavirus disease-2019 in cancer patients. A report of the first 25 cancer patients in a western country (Italy). Futur Oncol. 2020;16(20):1425-32.

19. Iaccarino G, Grassi G, Borghi C, Ferri C, Salvetti M, Volpe M. Age and Multimorbidity Predict Death among COVID-19 Patients: Results of the SARS-RAS Study of the Italian Society of Hypertension. Hypertension. 2020;366-72.

20. Bianchetti A, Rozzini R, Guerini F, Boffelli S, Ranieri P, Minelli G, et al. Clinical Presentation of COVID19 in Dementia Patients. J Nutr Heal Aging. 2020;24(6):560-2.

21. Deiana G, Azara A, Dettori M, Delogu F, Vargiu G, Gessa I, et al. Deaths in SARS-CoV-2 positive patients in Italy: The influence of underlying health conditions on lethality. Int J Environ Res Public Health. 2020;17(12):1-10.

22. Bonetti G, Manelli F, Patroni A, Bettinardi A, Borrelli G, Fiordalisi G, et al. Laboratory predictors of death from coronavirus disease 2019 (COVID-19) in the area of Valcamonica, Italy. Clin Chem Lab Med. 2020 Jun;58(7):1100-5.

23. The European House. 14th Meridiano Sanità: Le coordinate della salute - Rapporto 2019. November 1. House TE, editor. Roma; 2019.

24. Confortin SC, Meneghini V, Ono LM, Garcia KC, Schneider IJC, D’Orsi E, et al. Indicadores antropométricos associados à demência em idosos de Florianópolis - SC, Brasil: Estudo EpiFloripa Idoso. Cien Saude Colet. 2019 Jun;24(6):2317-24. 